\title{
Development of Intelligent Multi-agents System for Collaborative e-learning Support
}

\author{
Issam Matazi ${ }^{1}$, Rochdi Messoussi ${ }^{2}$, Salah-Eddine Bellmallem ${ }^{3}$, Ilham Oumaira ${ }^{4}$, Abdellah Bennane $^{5}$, \\ Raja Touahni ${ }^{6}$ \\ 1,2,3,6 LASTID, faculté des sciences de Kenitra, Université Ibn Tofail, Kenitra, Morroco \\ ${ }^{4}$ ENSA, Kenitra, Morocco \\ ${ }^{5}$ LIMIARF UM5 \& CFIE Rabat, Morocco
}

\begin{tabular}{l} 
Article Info \\
\hline Article history: \\
Received Feb 03, 2018 \\
Revised Apr 04, 2018 \\
Accepted Apr 28, 2018
\end{tabular}

\section{Keywords:}

Collaborative e-learning

Fuzzy logic

LMS

Multi-agent system

\begin{abstract}
The aim of this paper is the introduction of intelligence in e-learning collaborative system. In such system, the tutor plays an important role to facilitate collaboration between users and boost less active among them to get more involved for good pedagogical action. However, the problem lies in the large number of platform users, and the tutor tasks become difficult if not impossible. Therefore, we used fuzzy logic technics in order to solve this problem by automating tutor tasks and creating an artificial agent. This agent is elaborate in basing on the learners activities, especially the assessment of their collaborative behaviors. After the implementation of intelligent collaborative system by using Moodle platform, we have tested it. The reader will discover our approach and relevant results.
\end{abstract}

Copyright $\odot 2018$ Institute of Advanced Engineering and Science. All rights reserved.

\section{Corresponding Author:}

Issam Matazi,

LASTID, faculté des sciences de Kenitra, université Ibn Tofail, Kenitra, Morroco

Email: iss.matazi@gmail.com

\section{INTRODUCTION}

In e-learning collaborative system environment, the separation between learners in time and space requires a great effort to oversee the learning progress, the relevant level of communication, the collaboration among learners, and the support less active learners to avoid their isolation. That is why the role of the tutor in such system is learners support.

The use of artificial intelligence technics in e-learning platforms has improved its tools and facilitated advising of users [1].

Several research have been focusing on the tutor role in e-learning collaborative system and suggesting some solutions allowing better collaboration between learners and avoiding their isolation.

Soller proposed a model allowing detecting the interaction problems between group members [2]. Then MBALA proposed a multi-agents system (MAS) intended to be coupled with E-learning platforms to implement features that allow to estimate the group state as: present, absent, the percentage of active people, learner productivity, etc. [3]. Israel describes an Intelligent Collaborative Support System (ICSS) that supports a collaborative effort by analyzing and modifying the collaborative process dynamically while employing a web-based interface [4]. Djouad proposed tools to calculate the indicators of collaborative activities in a human learning environment [5]. Andi presented a approach to analyze the behavior of students in collaborative work. She proposed the degree centrality and eigenvector method for identifying the collaborative work of while in wiki e-learning. The log data of the Moodle e-learning system is observed that records the students' activities and actions while using wiki [6]. Christina proposed a model to predicting the 
presence of learning motivation in e-learning, and aim to assist teachers in identify whether student needs motivation [7].

These researches are based on different approaches that analyze learner traces such as interaction and communication between learners which calculate indicators providing information about collaborative behavior of learners, and determining their behavioral profiles [8]-[10]. The tutor uses this relevant information (indicators, profiles...) to properly evaluate the collaborative behavior of each individual learner and react with the appropriate way to improve it.

\section{PROBLEM}

We note that does some questions remain unresolved such as: the tutor is it able to manage a large number of platform users and their collaborative actions in terms of availability? Is he able to send recommendations and remarks to each student? Is it able to intervene in good deadlines?

Considering these constraints in terms of times, availabilities and possibilities, the tutor will be not able to address this challenge.

The tedious work can be delegating to machine learning, and allowing the tutor, time and efforts in order to stimulate thinking.

Considering these constraints in terms of feasibility, tutor availability, and then computerization and automation of tutor tasks become crucial.

In this direction, we have designed and implemented a multi-agents system, and integrated it to Moodle platform in order solve the problem above mentioned.

Our choice of using of MAS in online collaborative learning is justified by an interesting approach of intelligent collaborative systems design. It is characterizing by the distribution of the overall control system and the presence of autonomous agents operating in a shared and dynamic environment.

The fuzzy logic in terms of model and technics are used both modeling our multi-agents system and inferring the learning functions [9].

This paper is organized as follow: first, we present the model for collaborative e-learning and the architecture of multi agent system designed to automate support learners. Second, we describe the model of fuzzy logic and machine learning use in e-learning context. Third, we expose the implementation steps of system. Fourth, we present the experiment results and discussions. We end this paper by exposing conclusions and future works.

\section{MULTI-AGENT SYSTEM FOR AUTOMATING THE SUPPORT OF LEARNERS IN COLLABORATIVE E-LEARNING (SMAASA)}

3.1. Support Model for Collaborative e-learning

In face-to-face collaborative learning the tutor can observe the behavior of each learner; he can detect their level of involvement and intervene to guide or motivate them. In collaborative e-learning, this task becomes more complicated given the separation between tutor and learner. The support model that we propose to solve this problem is to allow the evaluation of the involvement level of each learner in a collaborative activity and sending instructions adapted to each of them.

Our idea is to exploit the interaction data between learners during the learning process to improve the level of collaboration. These data will be analyzed and stored as indicators in the learner profile. Based on these indicators, the system evaluates the state of collaboration of the learners, and then sends automatic recommendations to improve it. The process of supporting consists of two stages(see Figure 1).

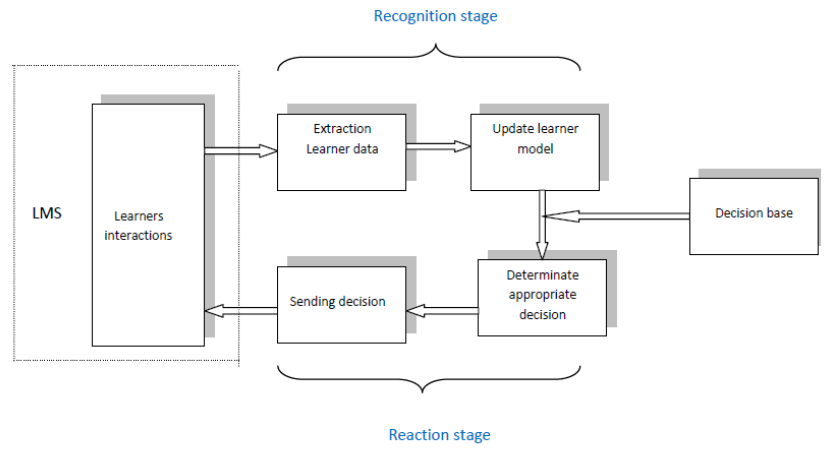

Figure 1. Support model for collaborative e-learning 
The recognition stage: the system identifies the learner's collaborative activity such as participation in forums, the filing of a proposal in a working group etc. Based on these activities a set of indicators are calculated and stored in the learner profile.

The reaction stage: during this stage the system determines the appropriate instructions and recommendations based on learner's collaboration level.

Based on this collaborative learning support model, we propose a multi-agent system which mission is the automation of tutor tasks. The automation of the system will be achieved based on the fuzzy logic technique.

\subsection{Fuzzy Logic}

Fuzzy logic is an extension of Boolean logic, it was proposed by Zadeh to model natural language and to account for the vague knowledge that we humans manipulate every day [11].He introduced the concept of fuzzy set to address the problems in many complex systems that need to process information that is imperfect nature, its basic concept is to graduate membership of a set, allowing to take into account the imprecision in knowledge and formalizing the process of human reasoning.

A fuzzy inference system is composed of three blocks:

The first block is the fuzzification block. It transforms numerical values into membership degrees to the different fuzzy sets of the partition. The second block is the inference engine, with the rule base.

IF (condition_1 [and / or] condition_2 [and / or] ... [and / or] Condition) THEN (actions in output variables).

The third one implements the defuzzification stage if necessary. It yields a crisp value from the rule aggregation result

\subsection{MAS and e-learning}

An agent is an autonomous entity, capable of communicating with other agents, as well as of perceiving and of representing his environment. Every agent makes specific actions according to the perception of his environment. A set of agents in interaction forms a multi-agents system.

Two categories of agents can be distinguished: the reactive agents and the cognitive agents[12].

The agents in a multi-agent system have several important characteristics [13]:

Autonomy: the agents are at least partially independent, self-aware, and autonomous.

Local views: no agent has a full global view of the system, that is to say the system is too complex for an agent to make practical use of such knowledge.

Decentralization: there is no designated controlling agent.

The use of the intelligent multi-agents system in e-learning field allows to solve some pedagogic problems by taking advantage of some characteristics. Examples: adaptation of the courses of learning( $[14] ;[15])$; the design of collaborative learning platform ([16];[17]); the individualization of the learning [18]; the support of the learners and the tutor.

By studying these works, we noticed that any process of adaptation is based on a model of the learner, a representation of its characteristics which the system takes into account

This modelling allows to give a description as complete as possible of all the aspects related to the behaviour of this user. In this work, we suggest bringing assistance to the community of learning on the basis of social behavioural side more than cognitive one. So, we use indicators which inform about the behavioural profiles (social) of the learners.

In the next section we present the architecture of our intelligent multi-agent system for supporting learners in a Collaborative e-learning Platforms (SMAASA).

\subsection{Architecture system}

Based on the support model of learner, the architecture system consists of three layers (Figure 2):

The learner layer: is the interface interaction between the learner and the system. 


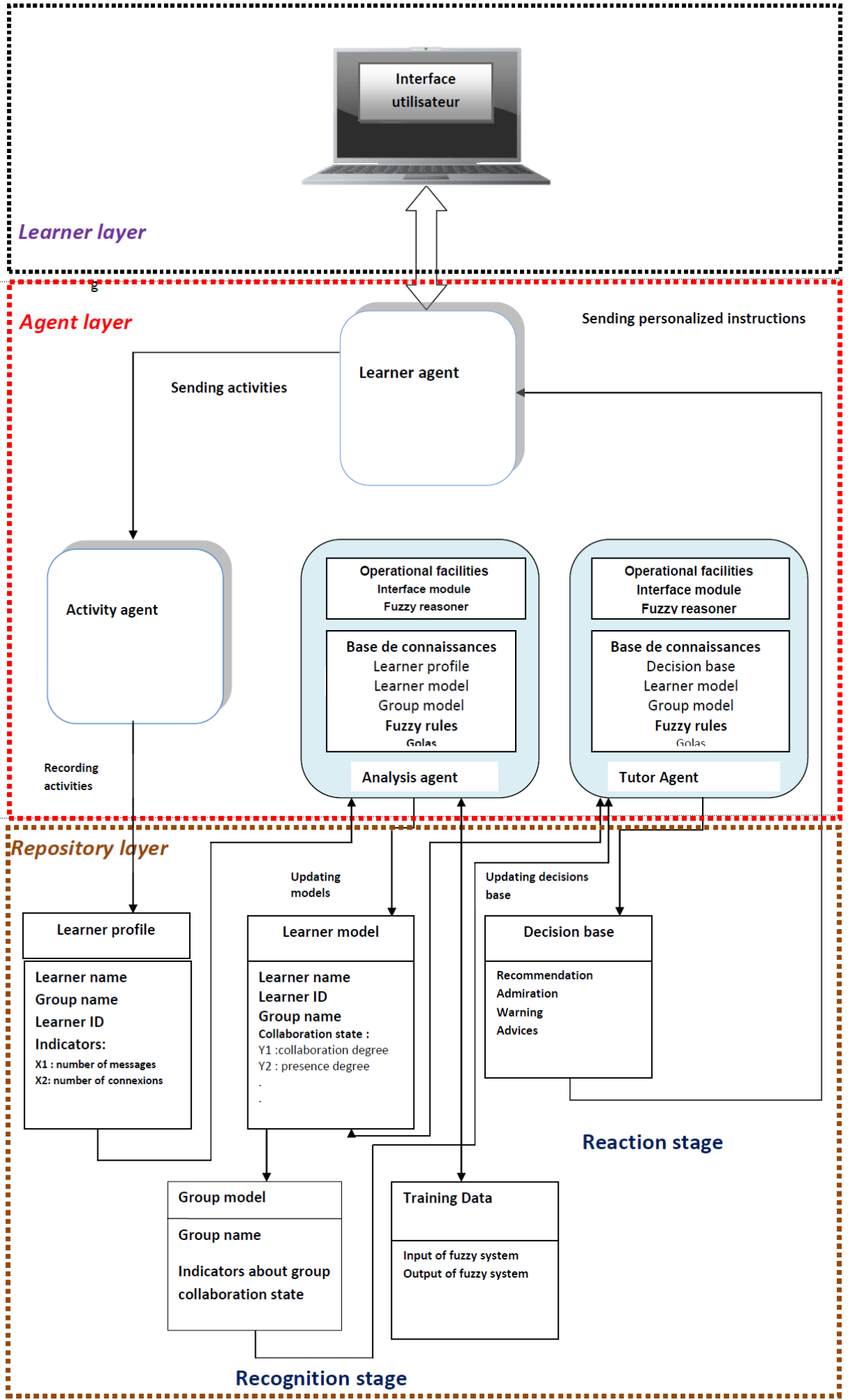

Figure 2. Architecture system

The agent layer: contains a number of cognitive and reactive agents:

- Activity agent: a reactive agent, from the collaborative activities of the learner, such as participation in forums, message exchange, the depositing of documents, it calculates indicators that will be stored in the profile learner 
- Analysis agent: a fuzzy agent whish the role is to evaluate automatically the collaborative learner level using fuzzy logic technique based on indicators stored on the learner profile. It feed and updates the learner model and update fuzzy rules.

- Tutor agent: a fuzzy agent, responsible for the automation of decision that allow to improve the collaborative behavior of learners following the evaluation result made by analysis agent. It sends the appropriate recommendations to each learner and also performs the update of decisions base.

- Learner agent: produces a suitable interface for each student where he can receive messages, recommandations, warning etc based on the decisions base.

The repository Layer: This layer contains five components:

- The learner profile: includes the learner's static data such as name, code; and dynamic: indicators of its social behavior.

- The learner model: contains information about the learner collaborative behaviour: the collaborative degree, presence degree etc.

- The model group: contains information about groups collaborative behavior.

- The decisions Base: Contains the appropriate decisions to the various scenarios of behaviour and will be sent to learners depending on their collaboration level.

- Learning data: includes data about the inputs and outputs of the fuzzy system. The tutor agent is based on the training data to generate the rule base.

\section{FUZZY LOGIC INFERENCE MODEL TO EVALUATE THE LEARNER'S INVOLVEMENT IN A COLLABORATIVE ONLINE LEARNING}

We aim to have a fuzzy system which leads to estimate the degree of collaboration of every learner, or working groups in online collaborative learning. The system is based on indicators stemming from the analysis of the learner activities. The collaborative indicators represent the input of our fuzzy system.

Let $A=\left\{A_{1}, A_{1} \ldots \ldots . A_{i}, \ldots \ldots A_{k}\right\}$ the set of learner's collaborative actions .For each type of actions $A_{i}(i=1,2, \ldots . k)$, a measured numeric value $x_{i}(i=1,2, \ldots . k)$ is calculated for a student, example the action $A_{i}$ : sending messages with the value $x_{i}$ : number of messages sent by each student each measured numeric value $\left.x_{i}(i=1,2, \ldots . k)\right)$ takes its values in a universe of discourse $U_{i}(i=1,2, \ldots . k)$

Let $X=\left\{x_{1}, \ldots \ldots x_{i} \ldots \ldots . . . x_{k}\right\}$ the input of our fuzzy system with $x_{i} \in U_{i}, U_{i} \subset I^{+}$

Let $C_{j}(j=1,2, \ldots \ldots, L)$ the output of the system which represent different learning characteristics, such as level of collaboration, degree of implication. The process consists of three stages: fuzzification, inference, and defuzzification [19].

\subsection{Fuzzification}

This stage represents teacher's subjective linguistic $A=\left\{A_{1}, A_{1} \ldots \ldots A_{i}, \ldots \ldots A_{k}\right\}$.Each variable $A_{i}(i=1,2, \ldots . k)$ can take a different number of linguistic values $f_{i}$. The number $f_{i}$ of the linguistic values of each linguistic variable $A_{i}(i=1,2, \ldots . k)$ and their names $V_{i 1}, V_{i 2}, \ldots \ldots . V_{i f_{i}}$, are defined by the developer with the help from teachers, and depend on the variable $A_{i}(i=1,2, \ldots . k)$.

Let $T\left(A_{i}\right)=\left\{V_{i 1}, V_{i 2}, \ldots \ldots . V_{i f_{i}},\right\}$ the term set of $A_{i}(i=1,2, \ldots . . k)$.

For example, let us consider the linguistic variable $A_{i}=$ «time of task's execution » The corresponding term set could be:

$\mathrm{T}($ time of task'sexecution $)=\left\{\mathrm{V}_{\mathrm{i} 1,}, \mathrm{~V}_{\mathrm{i} 2}, \mathrm{~V}_{\mathrm{i} 3}\right\}=\{$ short, normal , long $\}$

At the fuzzification stage, the numeric input $X=\left\{\mathrm{x}_{1}, \ldots . \mathrm{x}_{\mathrm{i} \ldots \ldots . . .} \mathrm{x}_{\mathrm{k}}\right\}$, wherex $\mathrm{x}_{1} \in \mathrm{U}_{1}, \mathrm{x}_{2} \in$ $U_{2}, \ldots \ldots x_{k} \in U_{k}$, and $U_{i}$ is the universe of discourse of the ith input element $, U_{1}, U_{2}, \ldots . U_{k} \subset I^{+}$is fuzzified and transformed into membership degrees to the linguistic values $V_{i 1}, V_{i 2}, \ldots \ldots . V_{i f_{i}}$, which describe a student's behavior $A=\left\{A_{1}, A_{1} \ldots \ldots A_{i}, \ldots \ldots A_{k}\right\}$.

\subsection{Inference}

This stage represents teachers' reasoning in categorizing students qualitatively according to their abilities and personal characters. In particular, an approximation of fuzzy IF-THEN rules is performed, which represent teachers' reasoning in the qualitative assessment of students' characteristics. In our model, a qualitative description of a student's characteristics $\mathrm{C}_{1}, \ldots, \mathrm{C}_{\mathrm{j}}, \ldots, \mathrm{C}_{\mathrm{l}}$ is performed by treating student 
characteristics as linguistic variables. Each linguistic variable $C_{j}(j=1,2, \ldots, L)$ can take a different number of linguistic values $\mathrm{m}_{\mathrm{j}}$.

The set $T\left(C_{j}\right)=\left\{C_{j 1}, C_{j 2}, \ldots \ldots \ldots . . . C_{j m}\right\}$ is the term set of $C j(j=1,2, \ldots, L)$.

For example: if we treat the linguistic variable $\mathrm{C}_{\mathrm{j}}=$ "'student interest" using three linguistic values $\left(m_{j}=3\right)$, then the term set could be:

$\mathrm{T}\left(\mathrm{C}_{\mathrm{j}}\right)=\mathrm{T}$ ( student interest $)=\left\{\mathrm{C}_{\mathrm{j} 1}, \mathrm{C}_{\mathrm{j} 2}, \mathrm{C}_{\mathrm{j} 3},\right\}=\{$ neither interested, interested, very interested $\}$.

In this way, a mode of qualitative reasoning, in which the preconditions and the consequents of the IF-THEN rules involve fuzzy variables is used to provide an imprecise description of teachers' reasoning:

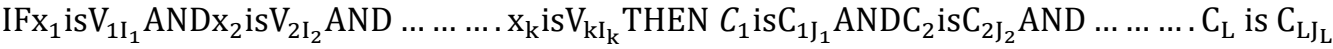

With $\quad \mathrm{I}_{1}=1,2, \ldots . . \mathrm{f}_{1} ; \mathrm{I}_{2}=1,2, \ldots \ldots \mathrm{f}_{2} ; \mathrm{I}_{\mathrm{k}}=1,2, \ldots \ldots \mathrm{f}_{\mathrm{k}} ; \mathrm{J}_{1}=1,2, \ldots \ldots . \mathrm{m}_{1} ; J_{2}=1,2, \ldots \ldots \mathrm{m}_{2} ; \mathrm{J}_{\mathrm{L}}=$ $1,2 \ldots . \mathrm{m}_{\mathrm{L}}$

Let $c_{j}=\left[c_{j 1}, c_{j 2}, \ldots \ldots . c_{j m j}\right](j=1,2, \ldots \ldots, L) \quad$ membership degree of output variable $C_{j}(j=$ $1,2, \ldots, \mathrm{L})$.

The inference stage, provides a fuzzy assessment $c_{j}=\left[c_{j 1}, c_{j 2}, \ldots \ldots . c_{j m j}\right](j=1,2, \ldots \ldots, L)$ of a student's characteristics, $C_{1}, \ldots, C_{j}, \ldots . C_{l}$ by assessing membership degrees $c_{j 1}, c_{j 2} \ldots . c_{j m_{j}}$ to the linguistic values $C_{j 1}, C_{j 2} \ldots \ldots C_{j m_{j}}$ of the linguistic variable $C_{j}(j=1,2 \ldots \ldots ; L)$ that describe the characteristic $C_{j}(j=$ $1,2 \ldots \ldots ; \mathrm{L})$

\subsection{Defuzzification}

This stage represents teachers' final decision in classifying a student in one of the predefined linguistic values $C_{j 1}, C_{j 2} \ldots . C_{j m_{j}}$ of the characteristic $C_{j}(j=1,2 \ldots \ldots ; L)$. This process is performed by weighting the fuzzy $\operatorname{assessmentc}_{j}(j=1,2 \ldots \ldots ; L)$. The fuzzy assessments $c_{j}=\left[c_{j 1}, c_{j 2}, \ldots \ldots c_{j m j}\right](j=$ $1,2 \ldots \ldots ; \mathrm{L})$ are defuzzified to non-fuzzy values, that is to say, to decisions on one of the linguistic values $\mathrm{C}_{\mathrm{j} 1}, \mathrm{C}_{\mathrm{j} 2} \ldots \ldots \mathrm{C}_{\mathrm{jm}}(\mathrm{j}=1,2 \ldots \ldots ; \mathrm{L})$ of the learning characteristic $\mathrm{C}_{\mathrm{j}}(\mathrm{j}=1,2 \ldots \ldots ; \mathrm{L})$.

\section{IMPLEMENTATION}

Our goal is to develop a system capable of grafting to the platforms of collaborative e-learning. For this purpose and in order that the system can have the ability of interoperability with several collaborative elearning platforms, the interaction between agents of systems and these platforms is done only through the analysis of the plateform's database. The system monitors a set of target tables to detect learner new activities (Figure 3).

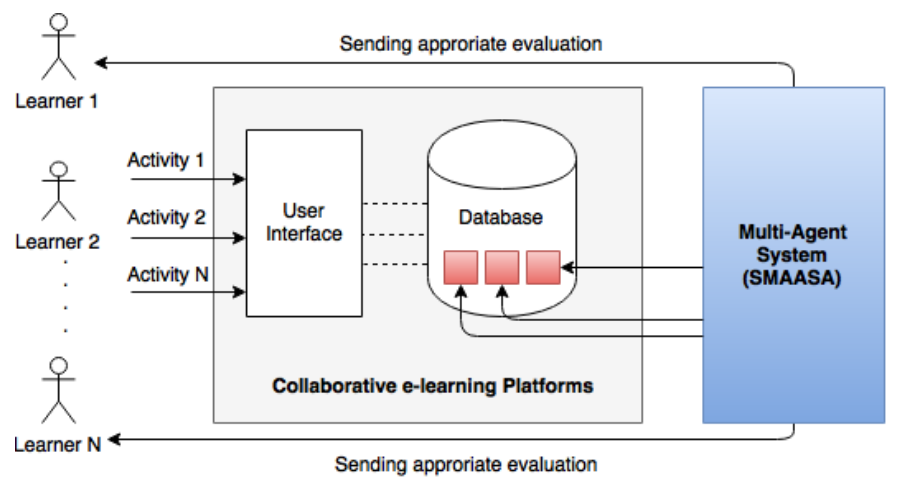

Figure 3. Interaction of the multi-agent system with the collaborative e-learning platforms

Thus, to implement our system, we choosed Java as a programming language because it met the system's requirements in terms of avaiblable implementations of the fuzzy logic technique, support for multiagent systems, access to databases and other well-known qualities of this language.

The agents of the system have been implemented through the JADE framework (Java Agent Development Framework) based on FIPA specifications [20]. The behavior which ensured the desired operations for the system's agents is the finite-state machine behavior. 
The inference systems have been implemented using jFuzzyLogic library [21], which offers mulitple features in relation with the fuzzy logic technique. A simulation of inference systems has already been made using FisPro [22], which is a software that allows to create fuzzy inference systems (FIS) from observed numerical data (learning data). In our case, this data represent the evaluations made by the human tutor (expertise). Thus, the goal is create fuzzy system that give tutor-like evaluations [23].

Therefore, three fuzzy inference systems were created based on fuzzy inference model datailled in paragraph 4. For its reasoning, the Analysis Agent uses two fuzzy inference systems (Figure 4 and 5 ) to infer the degree of collaboration, and the degree of presence, based on the activities that were detected by the Activity agent. The Tutor Agent uses the tirth fuzzy inference system (figure 6 ) to determine the degree of involvement of a learner based on the results found previously by the Analysis Agent, and then sends an appropriate instruction.

INPUTS

OUTPUT

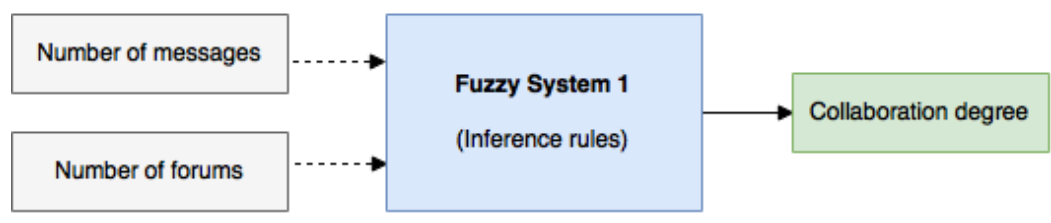

Figure 4. Inference system of colloration degree (FIS1)

INPUTS

OUTPUT

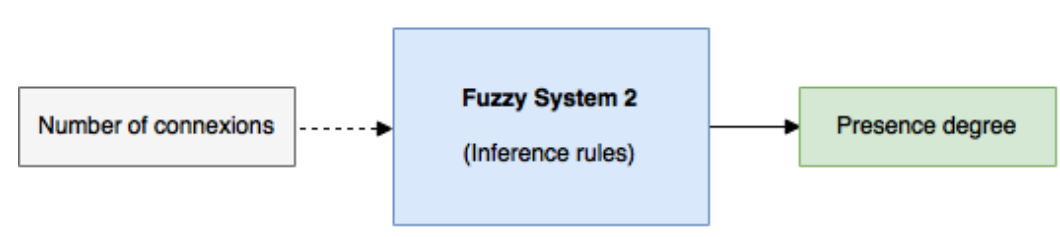

Figure 5. Inference System of Presence Degree (FIS2)

INPUTS

OUTPUT

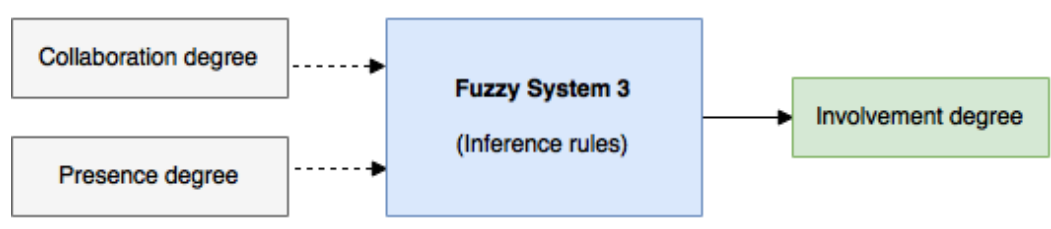

Figure 6. Inference system of involvement degree

We present as example the steps of creating inference systeme of collaboration degree (FIS1).

For FIS1 we have 2 input and 1 output $(k=1, L=1)$.

We determined linguistic values for each variable:

'Number of messages' is described with five linguistic values ( $f 1=3$ ) and by the term set :

$\mathrm{T}($ Number of messages $)=\left\{\mathrm{V}_{11}, \mathrm{~V}_{12}, \mathrm{~V}_{13}\right\}=\{$ weak, average, high $\}$

'Number of forums' is described with three linguistic values ( $f 2=3$ ) and by the term set:

$$
\mathrm{T}(\text { Number of forums })=\left\{\mathrm{V}_{21}, \mathrm{~V}_{22}, \mathrm{~V}_{23}\right\}=\{\text { weak, avearge }, \text { high }\}
$$

'Collaboration degree' is described with four linguistic values and by the term set $(\mathrm{m} 1=3)$ : 


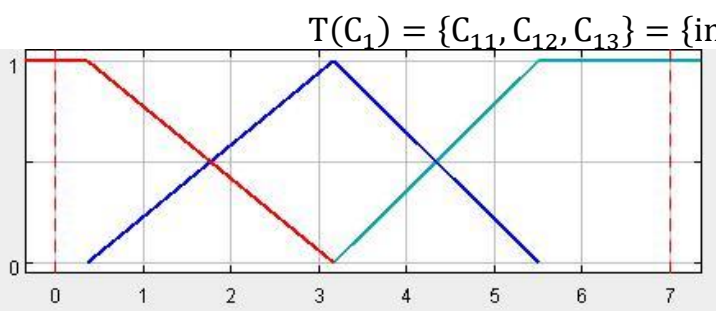

Figure 7. Membership function of 'number of messages'

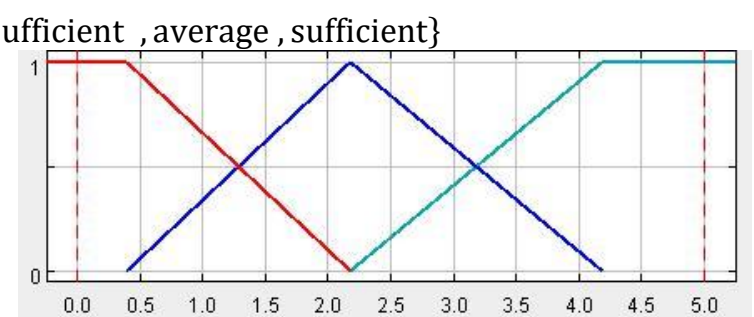

Figure 8. Membership function of ' number of forums'

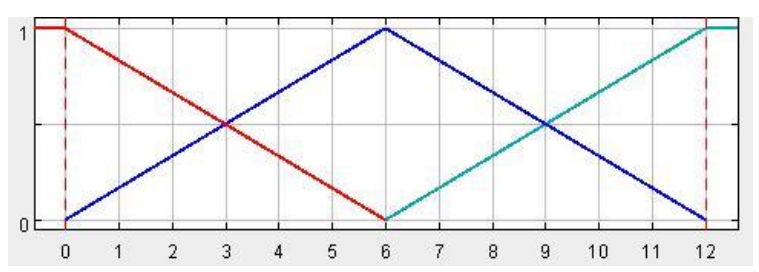

Figure 9. Membership Function of 'Collaboration Degree' $\mathrm{x}_{1}$

Rules Display
\begin{tabular}{|c|c|c|c|c}
\hline Rule & Active & IF Number of messages & AND Number of forums & THEN Collaboration degree \\
\hline 1 & $\boldsymbol{V}$ & avreage & & average \\
\hline 2 & $\boldsymbol{V}$ & weak & average & insufficient \\
\hline 3 & $\boldsymbol{V}$ & high & high & sufficient \\
\hline 4 & $\boldsymbol{V}$ & high & \\
\hline
\end{tabular}

Figure10. Fuzzy rules of FIS1

\section{EXPERIMENT}

The aim of this experiment is to test the system SMAASA in real learning situation to test and evaluate the contribution of the developed system concerning the improve of learner's involvement level during online collaborative activity.

\subsection{Description of the Experiment}

The experiment was conducted within the National School of Applied Sciences Kenitra with students of the fourth year specialty "Computer Engineering" and "industrial Engineering".The specialized course "Web technology" was an opportunity to involve students through a common project, related to the theme, to perform remotely via the e-learning Platform of the University Ibn Tofail (Moodle) [24].

The course "Web Technology" is taught over a period of 14 weeks. The method adopted in this course is a hybrid mode; students take 4 hours of class course and TP by week plus hours of online work to realize the duties requested by the tutor at the end of each week.At the beginning of the 11th week the tutor gave to the students a project to implement the knowledge acquired in the course. The aim of the project is to realize a web application to help candidates to prepare the driving license exam.

The teacher has set up in course space, a forum which the type is invisible group (the student can see only the messages of its affiliates) and an open forum accessible to all, where students can post bugs they can not solve.

The teacher asks students to only use of the forum as a communication tool and to avoid as much as possible using of social networks to discuss the project.

The 51 students involved in the experiment were divided into 14 groups of 3 to 4 members, The experiment was conducted over a period of 3 weeks (from December 25, 2015 to January 17, 2016).

At the end of each week the system is running in order to analyze the interactions between learners and subsequently evaluate the collaboration degree or collaborative behavior of each learner. Based on this evaluation, the system sends emails which are the subject of instructions and recommendations for each learner.

We have distinguished four types of messages:

Development of Intelligent Multi-agents System for Collaborative e-learning Support (Issam Matazi) 
Message type A: These are messages of admiration as the learner is working satisfactorily the learner is encouraged to continue with the same pace.

Message type B: these are messages intended for average learners, sent instructions in this case encourage learners and invite them to make more effort in collaborative behavior.

Message type C: These are messages for weak learners. The system recommends the learner to give more interest for collaborative activity and invited him to connect to the platform regularly.

Messages type D: messages of criticism and warnings for these learners almost missing on the platform.

\subsection{Results}

The system calculates the indicators: number of messages, number of discussions, number of connection do and therefore evaluates the degree of collaboration and degree of presence and the involvement level of each learner and each group by assigning marks between 0 and 20

We present descriptive statistics for the results obtained in the three periods of the experience for groups and for individuals learners

Table 1. Descriptive Statistics for the Groups and Idividuals Results

\begin{tabular}{llllllll}
\hline \multicolumn{1}{c}{ Periods } & $\begin{array}{c}\text { T1 } \\
\text { grp }\end{array}$ & indiv & $\begin{array}{c}\text { T2 } \\
\text { grp }\end{array}$ & indiv & $\begin{array}{c}\text { T3 } \\
\text { grp }\end{array}$ & indiv \\
\hline Av. Nbr message & 2,29 & 0,64 & 7,07 & 1,68 & 4,14 & 1,1 \\
Av. Nbr discussion & 1,93 & 0,54 & 5,79 & 1,32 & 3,79 & 1,02 \\
Av. Collaboration degree & 8,79 & 2,3 & 18,86 & 4,48 & 21,21 & 5,46 \\
Av. Implication level & 2,74 & 1,84 & 6,39 & 3,79 & 5,79 & 3,61 \\
Av. Presence degree & 4,1 & 3,03 & 7,52 & 5,23 & 8,68 & 6,55 \\
\hline
\end{tabular}

Av =average; $\mathrm{Nb}$ r=number; grp =groups; indiv =individuals

Based on this evaluation the system sends messages of recommendations which the type is A or B or $\mathrm{C}$ or $\mathrm{D}$ for learners and groups at the end of each period $\mathrm{T}$

Table 2. Types of Recommendations for Individuals and Groupes

\begin{tabular}{ccccccccc}
\hline Periods & A & & B & & C & \multicolumn{3}{c}{ D } \\
\hline T1 & grp & indiv & grp & indiv & grp & indiv & grp & indiv \\
T2 & 2 & 4 & 2 & 2 & 1 & 7 & 9 & 37 \\
T3 & 5 & 7 & 4 & 11 & 2 & 10 & 3 & 22 \\
Total & 11 & 4 & 2 & 8 & 8 & 17 & & 21 \\
\hline
\end{tabular}

By applying chi Square test on the results of the Table 2 we have shown that there is a dependency between variables periods $\mathrm{T}$ and type of recommendation as chi square value is superior than the Chi Square critical in both of individuals and groups results.

Table 3. Chi Square Test of Groups Results

\begin{tabular}{cc}
\hline Chi Square & 16,5909091 \\
\hline Chi Square Critical & 12,5915872 \\
\hline
\end{tabular}

Table 4. Chi Square Test on Individual Results

\begin{tabular}{cc}
\hline Chi Square & 17,8720588 \\
\hline Chi Square Critical & 12,5915872 \\
\hline
\end{tabular}

We show also that is a strong negative linear correlation between types of recommendations and periods (correlation coefficient $r=-0,32$ for groups results and $r=-0,17$ for individuals results). Then more we advance in time $(\mathrm{T} 1 \rightarrow \mathrm{T} 2 \rightarrow \mathrm{T} 3$ ), the recommendations is similar to the recoding of the minimum value $(D \rightarrow C \rightarrow B \rightarrow A)$. The following graphs illustrate these results: 


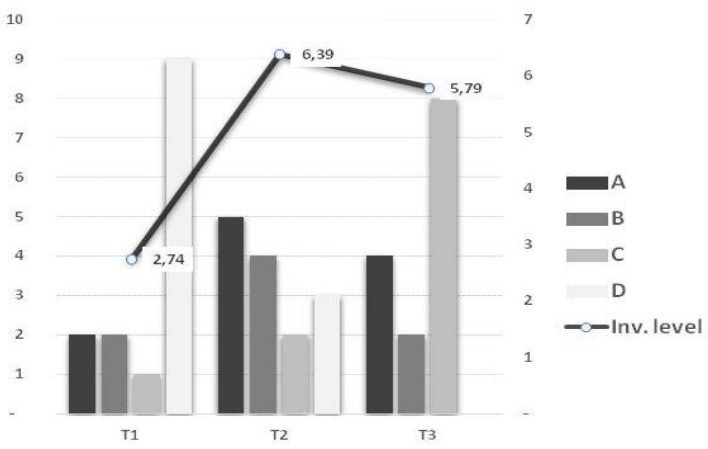

Figure 11. Evolution of Recommendations and Level of Groups

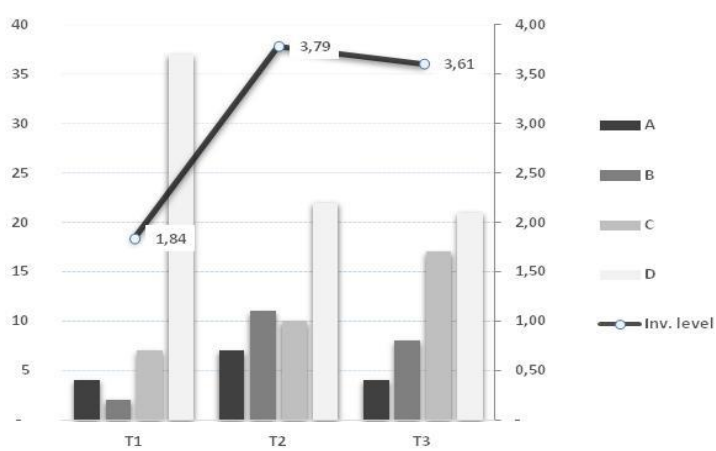

Figure 12. Evolution of Recommendations and Involvement Level of Individual Learners

\subsection{Discussion}

Our aim in this experiment is to verify that the SMAASA system by sending recommendations to each learner and each group has improved their collaborative behavior. The graphs above show the evolution of the involvement level and the types of recommendations compared to the three periods T1, T2 and T3 We see that there is an increase in the involvement level, especially in the period T2(from 1,84 to 3,79 for learners and from 2,74 to 6,39 for groups ) with showing that learners responded positively to messages sent by the system at the end of period T1. This also explains the increase in the number of recommendations of type A and B.

Type D recommendations characterized the $\mathrm{T} 1$ period as learners were not well involved in the activity on the platform. In the second period the A and B recommendations have progressed so there is an improvement. In the third period T3 there is a small drop in the level of involvement. This decrease is due to the circumstances of this period that passed the exams then the students connect but with less communication.

In order to collect the impressions of the tutors on the use of our system SMAASA, we carried out 3 direct interviews (at the end of each period) with the teacher responsible for the module who has been teaching for several years ) related to this module and the online tutoring.

Since the first interview, the tutor showed great interest in the results returned by the system. The tutor explained that he regularly (in previous years) did a manual analysis to identify the learners in difficulty as well as the groups that do not collaborate regularly in order to intervene with the learners concerned. The tutor confirmed to us that the automation of this task will certainly make the tracking of the learners less heavy than before.

The tutor appreciated the strong impact of the messages sent to the students at the end of the T1 period. He explained that he received several emails from the students who tried to justify their absence, for example, from group activities. Unlike us, the tutor was not surprised by the decline in the degree of collaboration during the $\mathrm{T} 3$ period, which is due to the occupation of the students by passing the theoretical exams.

To further analyze the data retrieved by the system, we sought to correlate the level of involvement of the groups with respect to the scores attributed by the teacher to the projects developed. However, the teacher explained that having a dynamic group whose members work together regularly is not necessarily reflected in the quality of the final project. This has a direct relationship to the level of each student in this module. Because within the same speciality, we find students with an excellent level in web development (due to self-training) as we can have average students who are satisfied with the knowledge acquired during the course and the tutorials in face-to-face. Thus, the final score assigned to a group and strongly linked to the preliminary level of the learners forming this group and the degree of collaboration within the group.

\subsection{System Performance}

SMAASA is a system for tutor's assistance in supporting, assessment and monitoring of learners. SMAASA like other systems cited in the introduction are based on the analyze of learner's traces generated during their online collaborative activities to provide indicator witch help tutors to evaluate learner's behavior (cognitive, social, ...) and intervene and remedy in a more relevant way. The performance of our SMAASA system compared to theses works is that it allows to automate the tasks of the tutor thus remedying the constraints related to the large amounts of data that provide these systems and which exceed the treatment capabilities of the human tutor. 
The inference process of the evaluation of the learner's involvement level by the fuzzy logic executed by SMAASA allowed us to have results much similar to those of the tutor (see figures 3 and 4). Based on this evaluation, SMAASA provide the appropriate recommendations to each learner and each group.

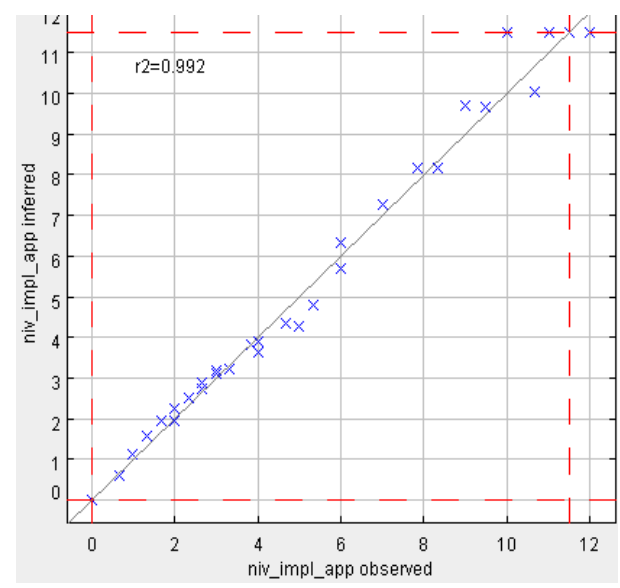

Figure 13. Comparison between Level of Involvement of Learners Observed and Inferred

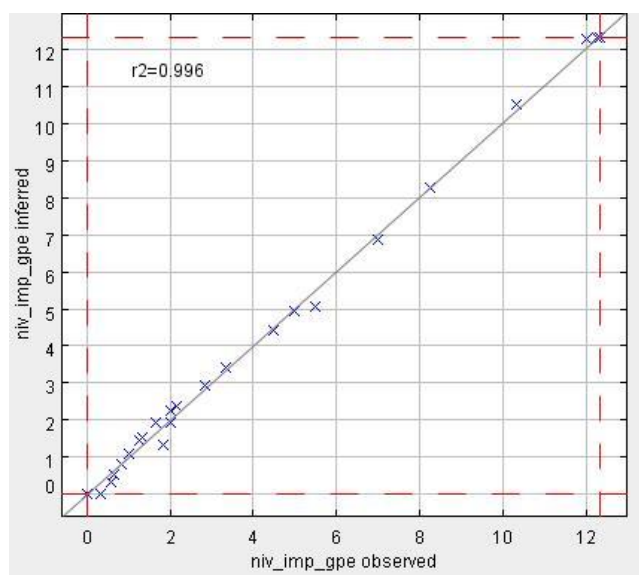

Figure 14.Comparaison between Level of Involvement of Goups Observed and Inferred

Note that the system is scalable and capable of assimilating other more complex indicators as regards the evaluation of the level of involvement of learners in an online collaborative activity.

\section{CONCLUSION}

The main objective this article was the realization of a multi agent system for automation of learner's support in a collaborative e-learning platform. Given the imprecise nature of manipulated information (learner's activities data), the automation of the process of evaluation of learner's collaborative behavior led us to provide the system's agents with fuzzy characteristics, as the fuzzy logic is a suitable solution to handle inaccuracies and uncertainties.

The conducted experiment to test the system showed that learners have reacted positively to the recommendations sent which explains the evolution of the level of involvement of the learners.

We denote that the system is scalable and able to assimilate other more interesting indicators regarding evaluation of learners involvement level in an online collaborative activity. For the moment we used only three indicators.

As perspective we aim to improve the prototype of our intelligent system by introducing algorithms for the generation and optimization of fuzzy rules to make it adaptive with new situations.

\section{REFERENCES}

[1] Potode A., Manjare M. E-Learning Using Artificial Intelligence. International Journal of Computer Science and Information Technology Research. ISSN 2348-120X (online) .2015;Vol. 3, Issue 1: pp: (78-82).

[2] Soller A. Supporting social interaction in an intelligent collaborative learning system. International Journal of Artificial Intelligence in Education (IJAIED). 2001 12, 40-62.

[3] Mbala A., Reffay C, \& Chanier T. SIGFAD: un système multi-agents pour soutenir les utilisateurs en formation à distance. Environnements Informatiques pour l'Apprentissage Humain . ATIEF; INRP ; 2003 : (pp. 329-330).

[4] Israel J , Aiken R. Supporting collaborative learning with an intelligent web-based system. International Journal of Artificial Intelligence in Education.2007; 17(1) : 3-40.

[5] Djouad T, Settouti L , Prié Y, Reffay C \& Mille A. Un Système à Base de Traces pour la modélisation et l'élaboration d'indicateurs d'activités éducatives individuelles et collectives, Mise à l'épreuve sur Moodle. TSI. $2010 ; 29(6)$ : 721-741.

[6] Aindi B, Norazah Y, et Ahmad H. The Analysis of Student Collaborative Work Inside Social Learning Network Analysis Based on Degree and Eigenvector Centrality, International Journal of Electrical and Computer Engineering (IJECE). 2016; Vol. 6, No. 5 : pp. 2488 2498

[7] Christina J, Arry A, Husni S et Iping S.Predicting the Presence of Learning Motivation in Electronic Learning: A 
New Rules to Predict, TELKOMNIKA. 2017; Vol. 15, No. 3 pp. 1223 1229

[8] Oumaira I, Messoussi R , \& Touahni R. Mise en expérimentation d'un système d'assistance au tuteur basé sur la réutilisation des indicateurs d'analyse automatique des interactions. Colloque Africain sur la Recherche en Informatique et en Mathématiques Appliquées CARI. 2010.

[9] Hror N , Messoussi R and Oumaira I. Social Learners' Profiles in a Distance Learning System Powered by a Social Network, International Journal of Advanced Computer Science and Applications(IJACSA). 2014; Vol. 5, No. $8:$ pp. 111-116.

[10] Chaabi Y, Messoussi R , Hilaire V, Ruichek Y, Lekdioui K \& Touahni R. Design of an Intelligent System to Support Tutors in Learning Communities Using Multi-Agent Systems and Fuzzy Logic. International Review on Computers and Software (IRECOS). 2015; 10(8) : 845-855.

[11] Zadeh L. A .Toward a theory of fuzzy information granulation and its centrality in human reasoning and fuzzy logic . Fuzzy sets and systems. 1997 ; 90(2):111-127

[12] Ferber J. Multi-agent systems: an introduction to distributed artificial intelligence.1995; Vol.1. Reading:AddisonWesley.

[13] Wooldridge, M. An Introduction to MultiAgent Systems. John Wiley \& Sons. 2002 ; ISBN 0-471-49691-X : p. 366.

[14] Bennane A. Adaptive educational software by applying reinforcement learning, Informatics in Education-An International Journal. 2013; Vol12_1:13-27.

[15] Xu D \& Wang H. Intelligent agent supported personalization for virtual learning environments. Decision Support Systems. 2006; 42(2): 825-843.

[16] Augustin J.P, Everton B and Vicari, R.M. Considering Student's Emotions in computational Educational System. XIV Simpósio Brasileiro de Informáticana Educação- NCE- IM/UFRJ. 2003.

[17] Viccari R. M Ovalle, D. A, \& Jiménez, J. A. ALLEGRO: Teaching/Learning Multi-Agent Environment using Instructional Planning and Cases-Based Reasoning (CBR,. CLEI). Electronic Journal. 2003 ; 10(1).

[18] Aouag S. Individualisation de l'apprentissage dans un Système Tuteur Intelligent: cas de l'apprentissage de la lecture dans un système AMICAL.(Doctoral dissertation, Université Blaise Pascal-Clermont-Ferrand II).2010.

[19] Stathacopoulou R , Grigoriadou M , Samarakou M \& Mitropoulos D. Monitoring students' actions and using teachers' expertise in implementing and evaluating the neural network-based fuzzy diagnostic model. Expert Systems with Applications. 2007 ; 32(4) : 955-975.

[20] Bellifemine F, Caire G , Poggi A \& Rimassa G.JADE: A software framework for developing multi-agent applications, Lessons learned. Information and Software Technology. 2008 ; 50(1):10-21.

[21] Cingolani P, \& Alcala-Fdez J. JFuzzyLogic: a robust and flexible Fuzzy-Logic inference system language implementation. FUZZ-IEEE. 2012: (pp. 1-8).

[22] Guillaume S \& Charnomordic . Learning interpretable fuzzy inference systems with FisPro. Information Sciences. $2011 ; 181(20): 4409-4427$.

[23] Matazi I. Messoussi R., \& Bennane A. The design of an intelligent multi-agent system for supporting collaborative learning. Intelligent Systems: Theories and Applications (SITA-14). 2014 : (pp. 1-8). IEEE.

[24] Romero C , Ventura S , \& García E. Data mining in course management systems: Moodle case study and tutorial. Computers \& Education.2008; 51(1) : 368-384. 